\title{
The Design of a Patient Transportation Robot's Lifting Arms Considering Comfort and Safety without the Presence of a Sheet
}

\author{
Yong-Hoon Lee, ${ }^{1}$ Bok-Soo Bae, ${ }^{1}$ Hong Jae Yim, ${ }^{2}$ and Yong-Kwun Lee ${ }^{3}$ \\ ${ }^{1}$ Environment Friendly and Advanced Safety Vehicle Engineering, Graduate School of Automotive Engineering, Kookmin University, \\ Jeongneung-dong, Seongbuk-gu, Seoul 136-702, Republic of Korea \\ ${ }^{2}$ Automotive Engineering, College of Engineering, Kookmin University, Jeongneung-dong, Seongbuk-gu, \\ Seoul 136-702, Republic of Korea \\ ${ }^{3}$ Center of Bionics, Korea Institute of Science and Technology, Hwarangno 14-gil 5, Seongbuk-gu, Seoul 136-791, Republic of Korea
}

Correspondence should be addressed to Yong-Kwun Lee, yklee@kist.re.kr

Received 7 September 2011; Accepted 28 September 2011

Academic Editor: Antonio Chella

Copyright (c) 2011 Yong-Hoon Lee et al. This is an open access article distributed under the Creative Commons Attribution License, which permits unrestricted use, distribution, and reproduction in any medium, provided the original work is properly cited.

\begin{abstract}
A transportation robot's lifting arms have an effect on the comfort and safety of patients. Improved arms have been designed through dynamic and static analyses to increase safety if a sheet not present on the lifting arms. To design the lifting arms, experimentation is very helpful, however, it is difficult and dangerous to experiment on patients; therefore, a simple human model was made and used for the dynamic analysis. Through the dynamic analysis results, a safe width and comfortable location for the lifting arms were determined. The thickness was then determined by static analysis and optimum design. In addition, tests have been conducted to confirm comfort and safety by deploying the designed lifting arms onto a transportation robot.
\end{abstract}

\section{Introduction}

Due to developments in science and medicine, the average lifespan of a man has increased. Since 2000, most advanced countries have entered into an aging society [1]; many elderly people are now experiencing physical handicaps. The number of handicapped people is also increasing due to an increase in traffic accidents and industrial disasters. Some of the handicapped patients cannot move by themselves, so they must receive help from a caregiver. It can be very difficult and dangerous to transfer them into a bed or a wheel chair. In order to solve this problem, the structure of the transportation or sliding mats have been used, however, these methods require human power [2]. For this reason, transportation robots that transfer the patients safely to a destination must be developed in order to ensure safety and efficiency. In this study, a transportation robot's lifting arms are designed through dynamic and static analysis using CAE, and then the lifting arms are optimized. In order to protect the patient, a sheet is normally hung on the lifting arms. However, if the sheet tears, the patient can fall from the lifting arms; there- fore, the lifting arms need to incorporate a design that does not require a sheet. Although experiments are very helpful to the design and analysis regarding the effects upon the lifting arm's interval and shape, it is difficult and dangerous to experiment using real patients. Accordingly, a simple human model has been incorporated the CAE and reappearance.

\section{The Human Body and Lifting Arm Modeling}

2.1. The Human Body Modeling. When lifting a human, it is very important to analyze the movement of a human through dynamic analysis. This is best done by using a simple human model. The human model was constructed using a 3D-CAD tool. The human model is $175 \mathrm{~cm}$ in height, the average stature of an adult man, and its mass is $65 \mathrm{~kg}$. The parts of the human model, which consist of a head, a neck, the upper parts of the body, a hip, arms, and legs, have been modeled as shown in Figure 1. The body segment mass determined by Rohrer Index is given in Table 1 [3]. Revolute joints and joint stiffness have been applied to each joint for dynamic analysis; the muscles are not considered. Joint stiffness is 


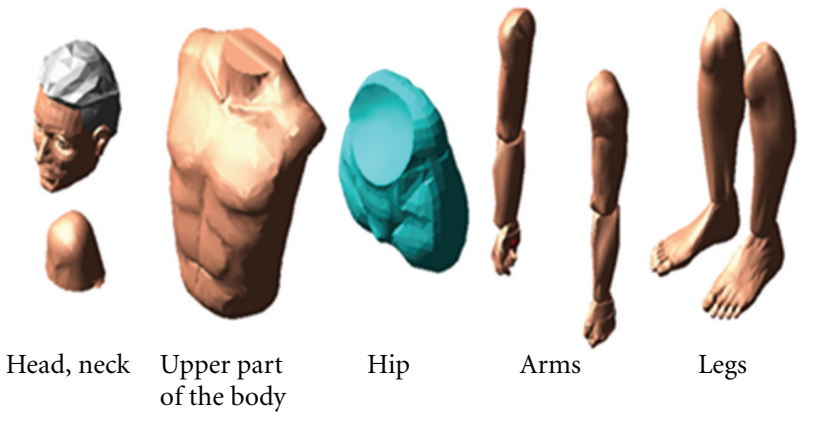

FIgURE 1: The parts of the human body.

TABLE 1: The body segment masses.

\begin{tabular}{lc}
\hline Body & Mass \\
\hline Head and neck & $6.28 \mathrm{~kg}$ \\
Upper body and hip & $32.00 \mathrm{~kg}$ \\
Arms & $6.10 \mathrm{~kg}$ \\
Legs & $20.26 \mathrm{~kg}$ \\
\hline
\end{tabular}

achieved through the use of torsion springs. Spherical joints and cylindrical joints would be more appropriate for the hip and the spine, as shown in Figure 2 [4], but for simplicity the revolute joint has been applied to all of the joints. Therefore, the motion in two dimensions instead the motion of in three dimensions was considered, since when lifting the human model, the parts of the human body are essentially bent over one centrally one-axis almost. The human spine is made up of 7 cervical vertebrae, 12 thoracic vertebrae, and 5 lumbar vertebrae, as shown in Figure $3[5,6]$. However, in order to simplify the human model, only one joint has been applied to the neck instead of 7 cervical vertebrae. In addition, five joints representing T1-T2, T9-T10, T12-L1, L2-L3, and L5were used instead of the 12 thoracic vertebrae and 5 lumbar vertebrae. The moment of inertia and the polar moment of inertia of the spine vertebra are given in Table 2 [4]. These have been applied to the upper part of the body. Then, stiffness coefficient of each joint was then considered [5-7].

The resulting stiffness $k$ was determined through the use of (1) [8]. The joint stiffness of the spine is originally nonlinear, so the mean value was applied. The joint stiffness of the patient should be accurately reflected in the joint, however, appropriate studies are rare. Therefore, the joint stiffness was based on a normal adult. Figure 4 shows the combination of the human parts by using revolute joints and torsion springs:

$$
\begin{gathered}
M_{c}=k \varphi[N \cdot m], \\
k=\frac{M_{c}}{\varphi}\left[N \cdot m \cdot \mathrm{deg}^{-1}\right] .
\end{gathered}
$$

2.2. The Lifting Arm Modeling. In this section, a dynamic analysis without a sheet is presented. Figure 5 shows the simulation results. It can be seen that the human model fell from the lifting arms due to their narrow width. Because this accident can occur, the width must be expanded to ensure that the device is safer. In order to determine the proper

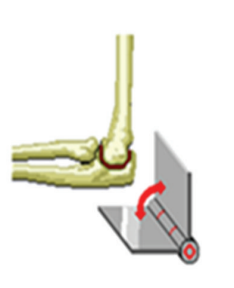

Elbow

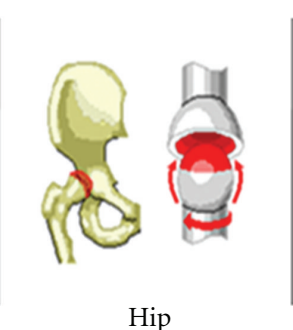

Hip

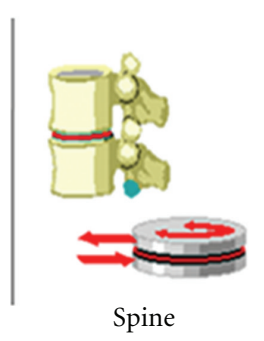

Figure 2: Human joints and their mechanical equivalent.

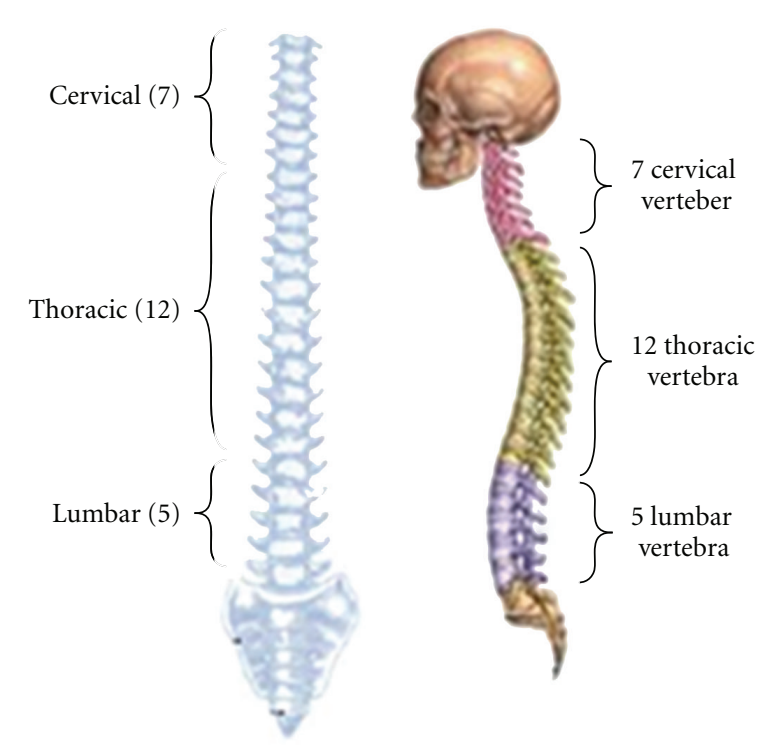

FIgURe 3: The human spine vertebra.
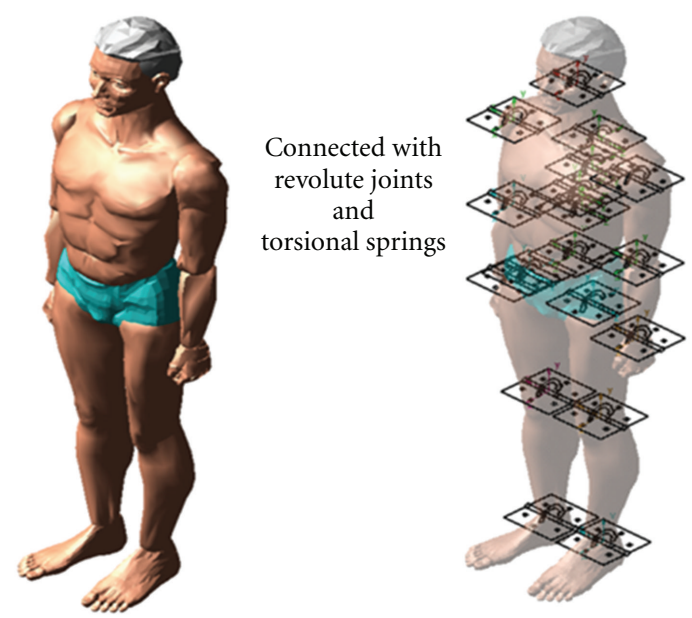

FIGURE 4: The combination of the human parts using revolute joints.

width through dynamic analysis, the initial lifting arms were modeled as shown in Figure 6 to analyze the movement of the human model according to width. The sheet hangs on the two lifting arms as shown in Figure 6, however it is not considered in this study because the sheet can be broken by an overload or by repeated loads. The width was increased 

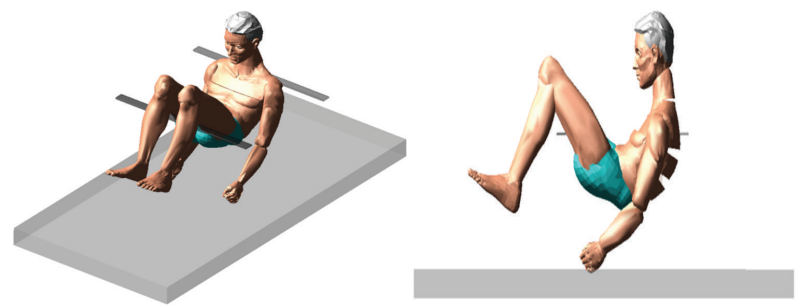

Figure 5: A fall from the lifting arms due to the narrow width.

TABLE 2: The structural properties of disks.

\begin{tabular}{lcc}
\hline Disk & $I x, I y\left(\mathrm{~mm}^{4}\right)$ & $J z\left(\mathrm{~mm}^{4}\right)$ \\
\hline T1-T2 & 25855 & 51709 \\
T9-T10 & 71819 & 143637 \\
T12-L1 & 128351 & 256701 \\
L2-L3 & 152647 & 305295 \\
L5-S1 & 192420 & 384841 \\
\hline
\end{tabular}

Hang on two lifting arms

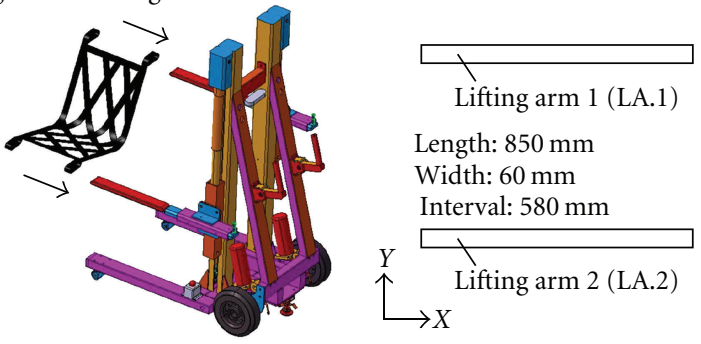

FIgURE 6: The initial model of the lifting arms.

by $10 \mathrm{~mm}$ intervals based on the initial model. Simulations were performed at each interval. It was found that when the width was $100 \mathrm{~mm}$, the human model sat stably in the lifting arms. Figure 7 shows the simulation results using the modified lifting arms. Through these results, it was confirmed that the human model sat more safely than it did before without a sheet. Despite the expanded width, without friction, the human model can fall. In order to prevent an accident, a substance-possessing friction must be applied to the lifting arms; moreover, a material that absorbs force should be added for comfort. When the dynamic analyzing was performed, the lifting arms were considered as to be a rigid body; therefore, there is no deformation. Consequently, the arm thickness will be determined by static analysis, and theory after the location of the lifting arms was determined through the dynamic analysis.

\section{The Dynamic Analysis}

3.1. The Location Determination. When lifting the human model, it is important to know the safest and most comfortable location for the lifting arms. The dynamic analysis was conducted for this purpose. The safest and most comfortable location regarding the torque between L2-L3 and L5-S1, T1$\mathrm{T} 2$ and T9-T10, and the contact force determined the initial
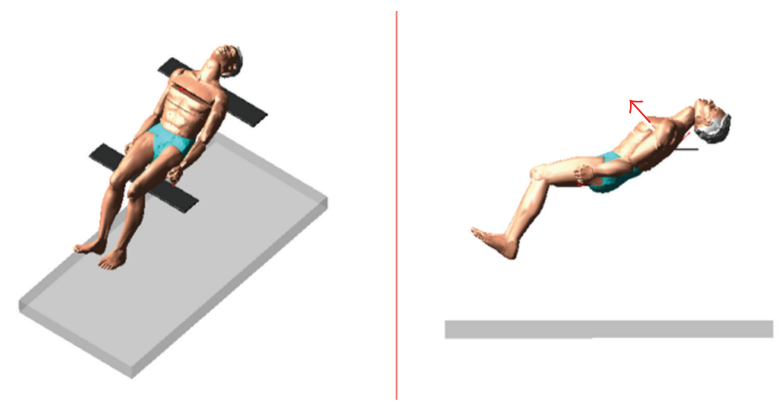

FIgURE 7: The simulation results.

location of the lifting arms, as shown in Figure 8. Here, the contact force is defined as the applied force at the upper body. If the calves of the legs are lifted, the joint force at the knee increases and the upper part of the body leans back, as can be seen in Figure 9. This initial location is entitled Case 1. The interval between the lifting arms was maintained. The lifting arms were moved to in the $+Y$-axis each at $10 \mathrm{~mm}$ intervals, and then the lifting arms were lifted up toward in the $+Z$ axis correctly for $800 \mathrm{~mm}$, respectively. LA. 1 was moved more than $200 \mathrm{~mm}$ to correctly sit position the human model.

The analysis was performed fifteen times according to the location of the lifting arms because on the sixteenth trial LA.1 lifted the neck instead of the upper part of the body. When determining the location of the lifting arms, it is very important to know how the torque and contact force change. The analyzed contact force is shown in Figure 10, Analysis 1, and the torque between L2-L3 and L5-S1 is shown in Analysis 2. The torque between T1-T2 and T9-T10 is shown in Analysis 3. The contact force (Analysis 1) and torque (Analyses 2,3 ) gradually decreased by about $27 \%, 74 \%$, and $83 \%$, respectively, based on the normalized value from Case 1 . In particular the results decreased in Case 13 because the hands are supported by LA.2. In addition, the lower part of the body is more supported by LA.2. These results show that the stress by contact force at the human spine is decreased. In addition, the torque between T1-T2 and T9-T10 increasingly reduced because the upper part of the body did not lean back, as shown in Figure 11 on the left. Namely, the best method is lift the end of the upper body and the end of the thigh by using LA. 1 and LA. 2 as shown in Figure 11 on the right.

3.2. The Analysis of an Elderly Person and Other Patients. This section confirms that an elderly person and other patients can be lifted safely at the determined location of the lifting 


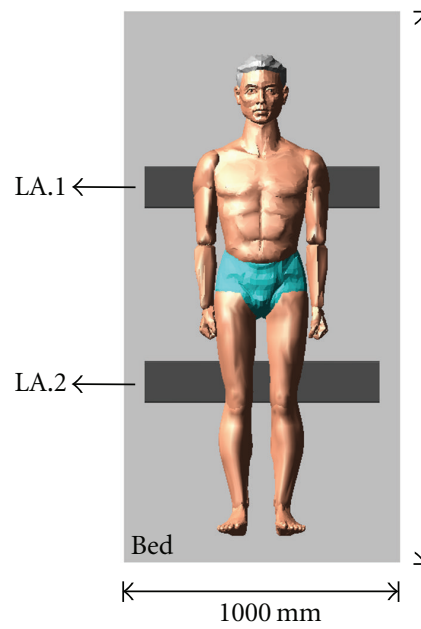

$2000 \mathrm{~mm}$
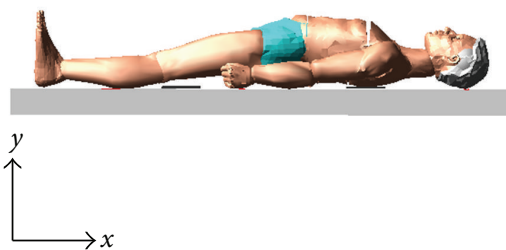

FIgURE 8: Finding the static equilibrium and initial location of the lifting arms.
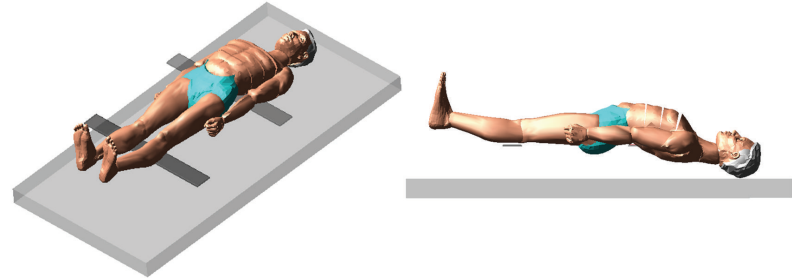

FIGURE 9: The lifting arm position causing a backwards lean.

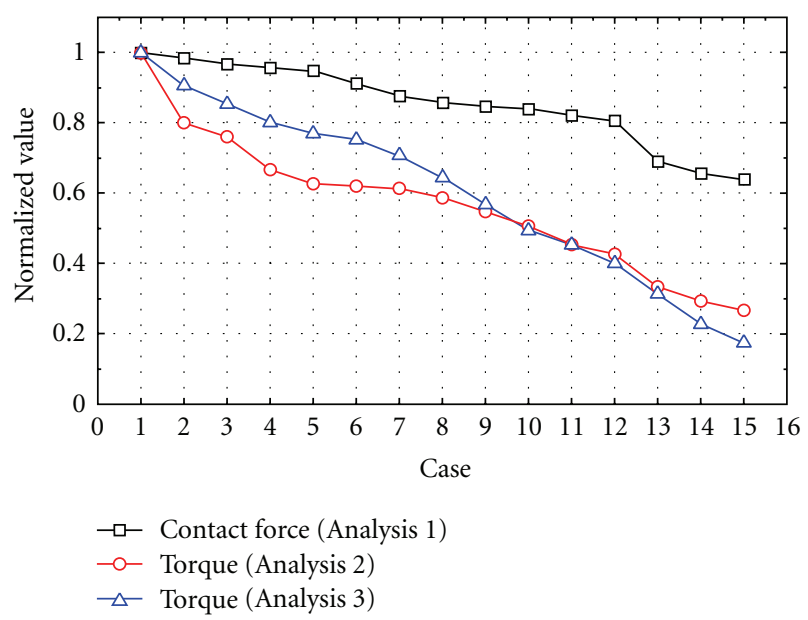

Figure 10: The dynamic analysis results.

arms by changing the joint stiffness of the patients. First, an elderly person was simulated, as shown on the left side of Figure 12, by changing the joint stiffness of the knees [9]. A patient paralyzed on the left side of the body was simulated, as shown on the right of Figure 12, by changing the joint stiffness of left body by about $1 / 10$. In addition, a patient with a broken leg in a cast was analyzed, as shown on the left side
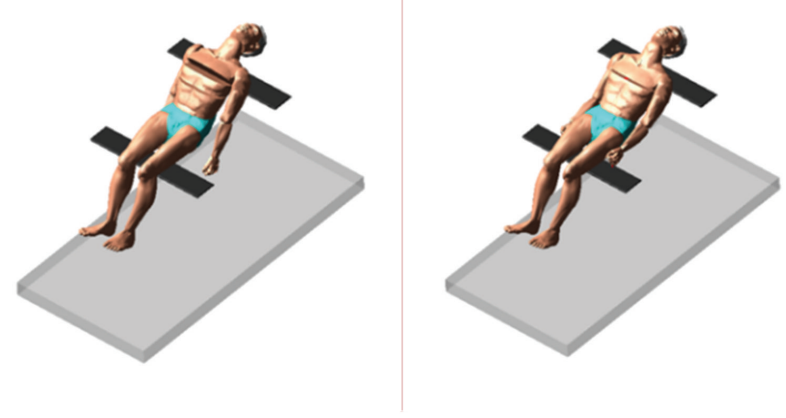

FIgURE 11: The simulation results comparison.
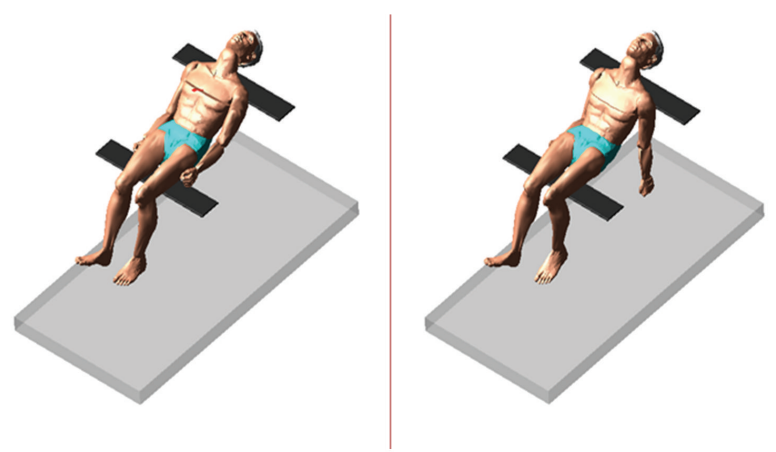

Figure 12: The analysis results for an elderly person and a patient paralyzed on the left side of the body.

of Figure 13, and an amputee was analyzed, as shown on the right side of Figure 13. The results confirm that if the lifting arms are placed in the location determined in the Section 3.1, an elderly person, patients, and the handicapped can be lifted safely. 

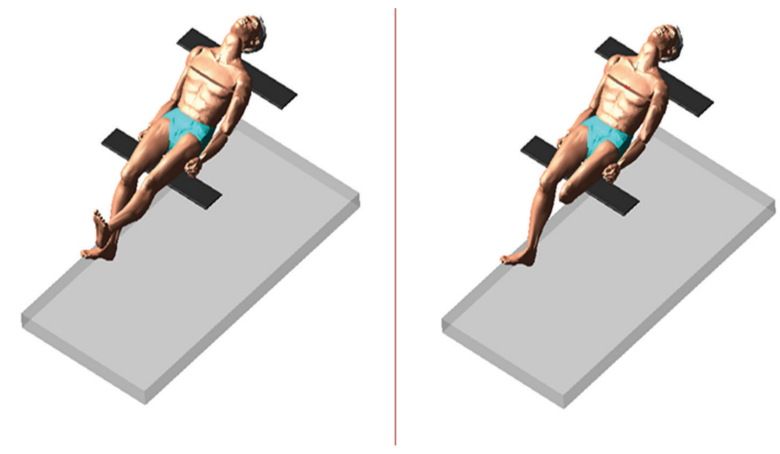

FIGURE 13: The analysis results for the other patients.

TABLE 3: The maximum deformation and stress comparison.

\begin{tabular}{lccc}
\hline Lifting arm & Results & $65 \mathrm{~kg}$ & $100 \mathrm{~kg}$ \\
\hline \multirow{2}{*}{ LA.1 } & $\delta_{\max }$ & $6.2 \mathrm{~mm}$ & $9.6 \mathrm{~mm}$ \\
& $\sigma_{\max }$ & $51.2 \mathrm{MPa}$ & $78.7 \mathrm{MPa}$ \\
\hline \multirow{2}{*}{ LA.2 } & $\delta_{\max }$ & $11.6 \mathrm{~mm}$ & $17.8 \mathrm{~mm}$ \\
& $\sigma_{\max }$ & $95.0 \mathrm{MPa}$ & $146.0 \mathrm{MPa}$ \\
\hline
\end{tabular}

\section{The Thickness Determination}

The maximum deformation $\left(\delta_{\max }\right)$ and stress caused by human weight were analyzed in order to determine the required thickness for the lifting arms. In order to achieve this, a finite elements model was made. The material used in the finite element model was A36 steel. The lifting arms were fixed by the supporting parts except for the $X$-axis translation; the lifting arms do not slide toward the $X$-axis owing to friction so the end of the lifting arm is fixed. When lifting a human using the two lifting arms, LA.1 and LA. 2 support about $35 \%$ and $65 \%$ of the weight, respectively. These results were derived from the dynamic analysis. The applied force is the distributed loading. However, the distributed loads have been changed into an intensive load for comparison using (2) [10]. First, when lifting the a $65 \mathrm{~kg}$ human, the maximum deformation was analyzed (thickness: $10 \mathrm{~mm}$ ) through a static analysis. The maximum deformation was $6.2 \mathrm{~mm}$ and $9.6 \mathrm{~mm}$ for LA.1 and 2, respectively. In addition, a corpulent $100 \mathrm{~kg}$ human has been considered. The maximum deformation and stress are indicated in Table 3 . The stress does not exceed the yield stress $(250 \mathrm{MPa})$, but the deformation may impede the movement of the lifting arms in the $X$-axis. Therefore, the thickness must be increased.

To theoretically confirm the results, the lifting arms are considered as cantilever beams, as shown in Figure 14. The $\delta_{\max }$ of the cantilever beam can be expressed as:

$$
\delta_{\max }=\frac{5 P L^{3}}{48 E I}\left(I=\frac{b h^{3}}{12}\right)
$$

when lifting a $65 \mathrm{~kg}$ human, the length $(L)$ is $765 \mathrm{~mm}$ except for the fixed part, and the load $(P)$ is $223 \mathrm{~N}$. The Young's modulus (E) is $200 \mathrm{GPa}$ (A36 steel) and the moment of in-

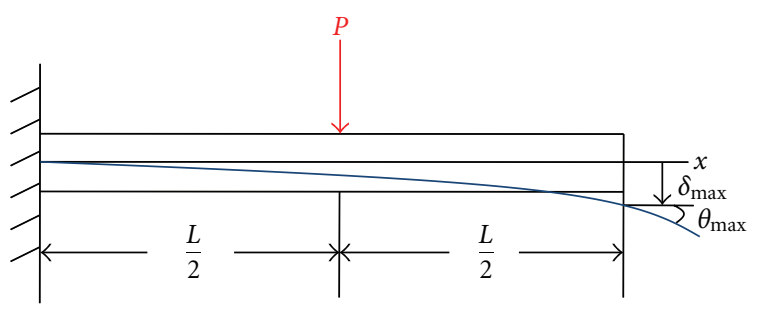

FIGURE 14: The lifting arm considered as a cantilever beam.

ertia $(I)$ is $8.3 \times 10^{3} \mathrm{~mm}^{4}$. The edge fillet $(5 \mathrm{~mm})$ is not considered. The $\delta_{\max }$ is $6.26 \mathrm{~mm}$.

The analysis result was $6.2 \mathrm{~mm}$ with an error of $0.1 \%$. This result shows that there is nearly no difference between the analysis results and the calculated results. Therefore, the thickness can be determined by using (2). The design constraint is

$$
\delta_{\max } \leq 3.0 \mathrm{~mm} \text {. }
$$

The $\delta_{\max }$ can be expressed as follows by (2):

$$
\begin{gathered}
\frac{60 P L^{3}}{48 E b h^{3}} \leq 3 \mathrm{~mm}, \quad h^{3} \geq \frac{60 P L^{3}}{3(48 E b)}, \\
h \geq \sqrt[3]{\frac{60 P L^{3}}{3(48 E b)}} .
\end{gathered}
$$

The thickness $(h)$ of LA.2 has been calculated for a $100 \mathrm{~kg}$ human. The thickness is $18.1 \mathrm{~mm}$. If the thickness is designed to be greater than the calculated results, $\delta_{\max }$ does not exceed $3.0 \mathrm{~mm}$. In this study, the thickness was determined to be $20 \mathrm{~mm}$. The thickness of LA. 1 is $20 \mathrm{~mm}$ as well, because LA. 1 can be used as LA.2 according to the method used to lift the patients.

\section{The Lifting Arm Optimum Design}

5.1. The Design Variable and the Objective Function. The cross section of the lifting arms has been optimized to be lightweight. The width and thickness were determined in Sections 2.2 and 4 . The area of was calculated by multiplying the width by the thickness and the mass determined by multiplying the volume by the density.

The derived masses are large; therefore, an optimum design must be accomplished. In order to optimize the rectangular cross section, as shown in Figure 15, the design variable and the objective function must be determined [11]. The design variable is height $(h=x)$. The width $(b)$ is not a design variable because the numerical value (LA. 1 and $2=$ $100 \mathrm{~mm}$ ) is fixed for safety. In this study, the thickness $(t)$ is $5 \mathrm{~mm}$. Therefore, only the height is a design variable. The objective function is to minimize the mass. The objective function can be expressed by a variable as

$$
\text { minimize } f(x)=\rho L[100 x-90(x-10)] .
$$

5.2. The Design Constraints. The $\delta_{\max }$ must not exceed $3 \mathrm{~mm}$. This is the first design constraint. The first constraint 


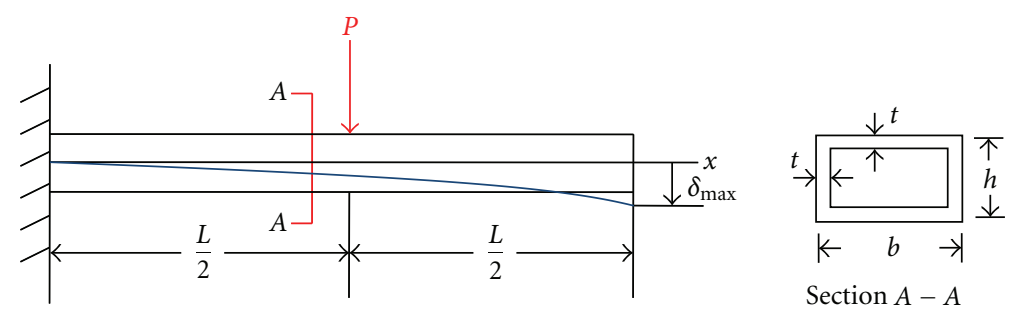

FIGURE 15: The cross section of the lifting arm.
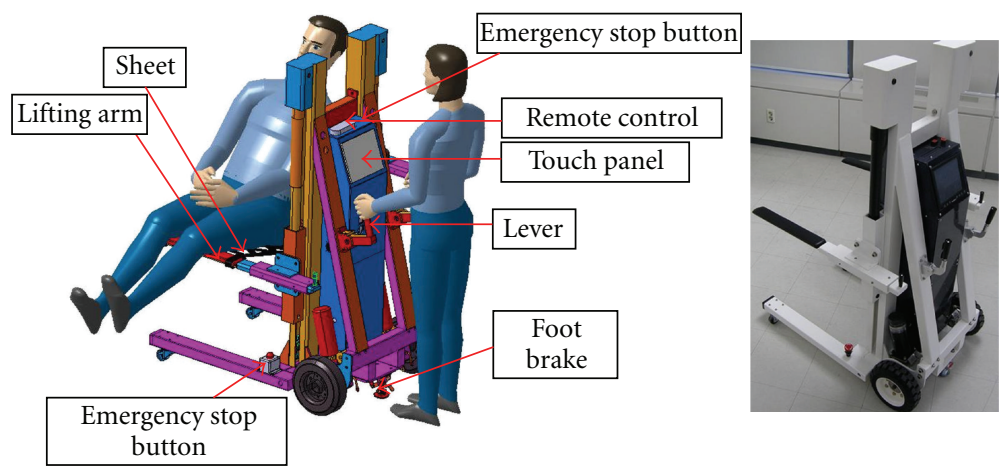

3D CAD model

Patient transportation robot

FIGURE 16: The patient transportation robot.

TABLE 4: The static analysis results for the base and optimized models.

\begin{tabular}{lcc}
\hline Model & Area & Mass \\
\hline Base model & $2.00 \times 10^{3} \mathrm{~mm}^{2}$ & $12.01 \mathrm{~kg}$ \\
Optimized model & $1.12 \times 10^{3} \mathrm{~mm}^{2}$ & $6.73 \mathrm{~kg}$ \\
\hline
\end{tabular}

equation is derived from (4). The constraint equations of LA. 1 and 2 can be written in the standard form as

subjec to, $\quad g_{1}=\frac{9150 \times 10^{2}}{\left[100 x^{3}-90(x-10)^{3}\right]}-1 \leq 0$.

The second design constraint can be expressed as

$$
\text { subjec to, } g_{2}=-x \leq 0 \text {. }
$$

The thickness that satisfies the objective function and the design constraints has been calculated. The optimized height is $22.1 \mathrm{~mm}$. Through this optimum design the mass has been reduced by about $43 \%$. To verify the results, a static analysis has been conducted resulting in consequence, a $\delta_{\max }$ of $2.99 \mathrm{~mm}$. In addition, the maximum stress has been analyzed. The stress has does not exceeded the yield stress. The area and mass of the base model and optimized model are summarized in Table 4.

\section{The Robot Components and the Test Results}

The designed lifting arms have been deployed into the patient transportation robot, as shown in Figure 16. The material that absorbs force has been attached onto the lifting arms. The robot consists of two wheels, two casters, two lifting arms, two emergency stop buttons, a foot brake, a touch panel, and a sheet. The robot is designed to move between beds and to seat the patient in a wheelchair. The process is laid out and has been tested, as shown in Figure 17. In order to reduce the noise, two wheels are moved by the motor and two casters support the front of the robot. Two emergency stop buttons and a foot brake are supplied to prevent accidents. The mass of the robot is $120 \mathrm{~kg}$ and its height is $1400 \mathrm{~mm}$. If the patient can walk, the robot can be used as a walking assistant robot when the patient's arms are leaned against the two lifting arms. Figure 18 shows the control architecture and the relationship among the electrical parts for the lifting robot. It consists of actuators, sensors, a control module, a power supply module, a driver module, and a user interface. The user interface module consists of 2 driving sticks, an LCD monitor, a remote controller, and a speaker which helps and guides the user in handling the robot easily.

\section{Conclusions}

In order to lift a patient safely, a sheet is hung on the lifting arms of a transportation robot. However, if the sheet fails, the patient can fall from the lifting arms; therefore, the lifting arms have to be designed with this in mind. For this reason, to lift patients safely without a sheet, the necessary width for the lifting arms has been determined. In addition, a safe and comfortable location for the lifting arms has been determined by analyzing the reaction force and torque in taken from a simple human model through dynamic analysis 

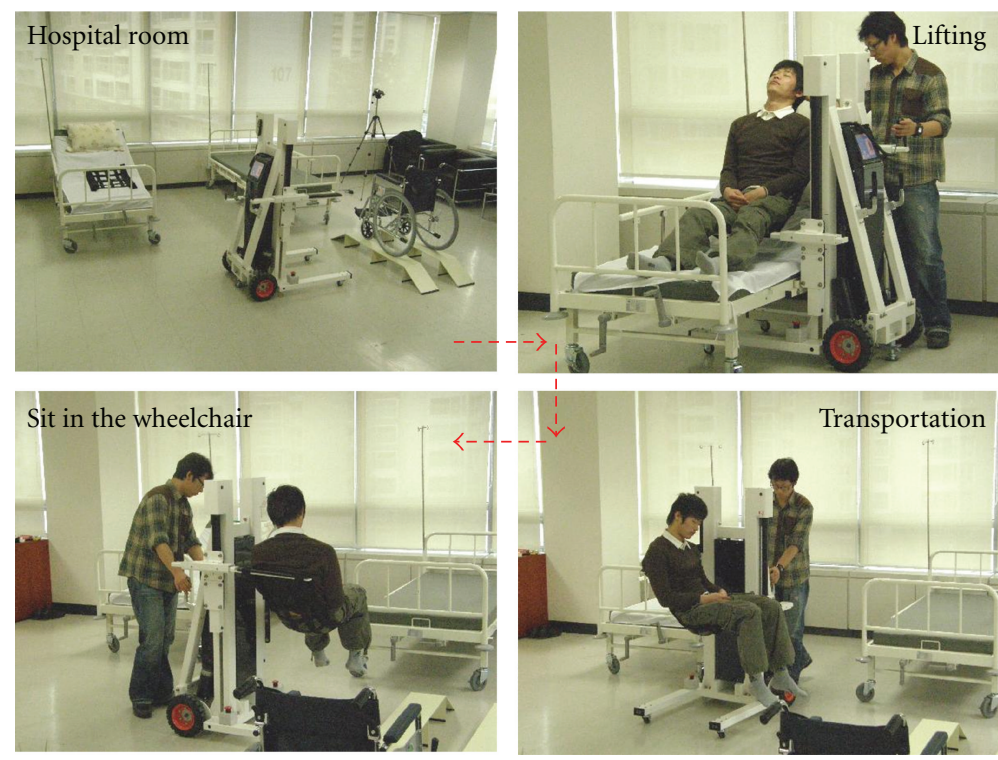

FIGURE 17: The transportation process.

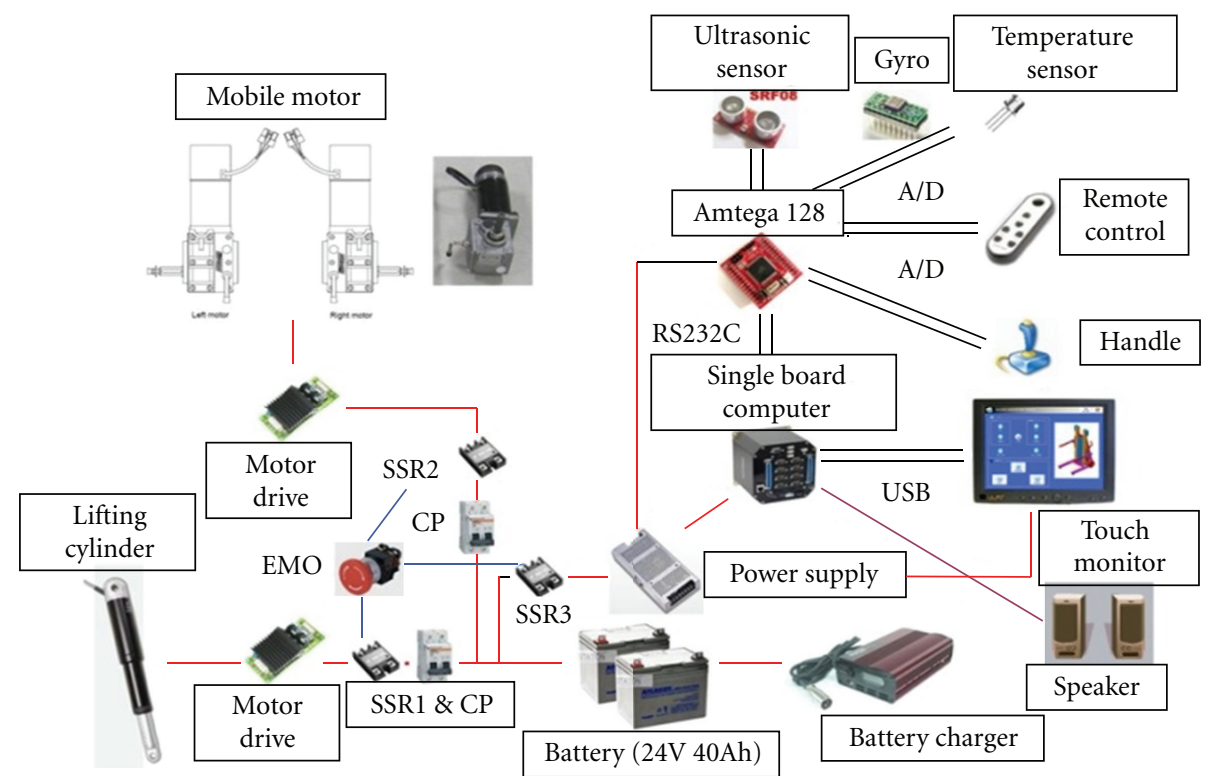

Figure 18: The control architecture and relationships.

instead of the difficult experiment. Using the dynamic analysis results, the contact force (Analysis 1) and the torque (Analyses 2,3 ) have been reduced by about $27 \%, 74 \%$, and $83 \%$, respectively. The thickness has been determined through static analysis and then an optimum design was conducted to make the arms lightweight. Through the optimum design, the mass of a lifting arm has been reduced by about $43 \%$. Based on the results obtained from the analysis and optimum design, the lifting arms were designed and deployed into a patient transportation robot. Tests were then conducted. The results show that the robot can lift a human safely and comfortably without a sheet.

\section{Nomenclature}

$M_{c}$ : General moment

$\varphi:$ Rotational angle

$k$ : Rotational stiffness

$P$ : Applied force on the lifting arms

$L$ : Length of the lifting arms

E: Modulus of elasticity

I: Moment of inertia of the cross-sectional area computed about the neutral axis

$b$ : Width of the lifting arm

$h$ : Thickness of the lifting arm. 


\section{Acknowledgments}

This research has been supported by the $21 \mathrm{C}$ Frontier $\mathrm{Na}$ tional Research Program and carried out with the Technical Support of the Center for Cognitive Robotics Research in KIST and Bobath Memorial Hospital.

\section{References}

[1] N. L. Ki, Y. J. Jae, S. J. Doo, and K. L. Sung, "Activities of daily living and instrumental activities of daily living of elderlies in Chollabuk-do area," Korea Association of Agriculture Medicine, vol. 25, pp. 65-83, 2000.

[2] S. P. Jang, "Development of the patient transportation robot," KISTI, 2004.

[3] S. C. Park and S. J. Park, "A study on the biomechanical body segment parameters of Korea adults," Korean Association of Physical Anthropologists, vol. 9, pp. 91-99, 1996.

[4] A. Kiefer, A. Shirazi-Adl, and M. Parnianpour, "Stability of the human spine in neutral postures," European Spine Journal, vol. 6, no. 1, pp. 45-53, 1997.

[5] S. Uchida, S. Komada, and J. Hirai, "A study about the posture and joint stiffness at stationary force control of human arm," in Proceedings of the 8th IEEE International Workshop on Advanced Motion Control (AMC '04), pp. 359-362, March 2004.

[6] W. H. Hsu, J. A. Fisk, Y. Yamamoto, R. E. Debski, and S. L. Y. Woo, "Differences in torsional joint stiffness of the knee between genders: a human cadaveric study," The American Journal of Sports Medicine, vol. 34, no. 5, pp. 765-770, 2006.

[7] Z. Horak, L. Jirkova, P. Tichy, and R. Sedlacek, "Experimental measurements of the lumbar spine stiffness," in Proceedings of the 22nd Danubia-Adria Symposium on Experimental Methods in Solid Mechanics (DAS '05), Parma, Italy, 2005.

[8] L. Jirkova, Z. Horak, R. Sedlacek et al., "Preliminary measurements of lumbar spine kinematics and stiffness," in Proceedings of the 5th Australasian Congress on Applied Mechanics, Brisbane, Australia, December 2007.

[9] S. D. Lark, J. G. Buckley, S. Bennett, D. Jones, and A. J. Sargeant, "Joint torques and dynamic joint stiffness in elderly and young men during stepping down," Clinical Biomechanics, vol. 18 , no. 9, pp. 848-855, 2003.

[10] R. C. Hibbeler, Mechanics of Materals, Prentice Hall, Upper Saddle Ridge, NJ, USA, 5th edition, 2005.

[11] S. A. Jasbir, Introduction to Optimum Design, Academic Press, San Diego, Calif, USA, 2nd edition, 2004. 

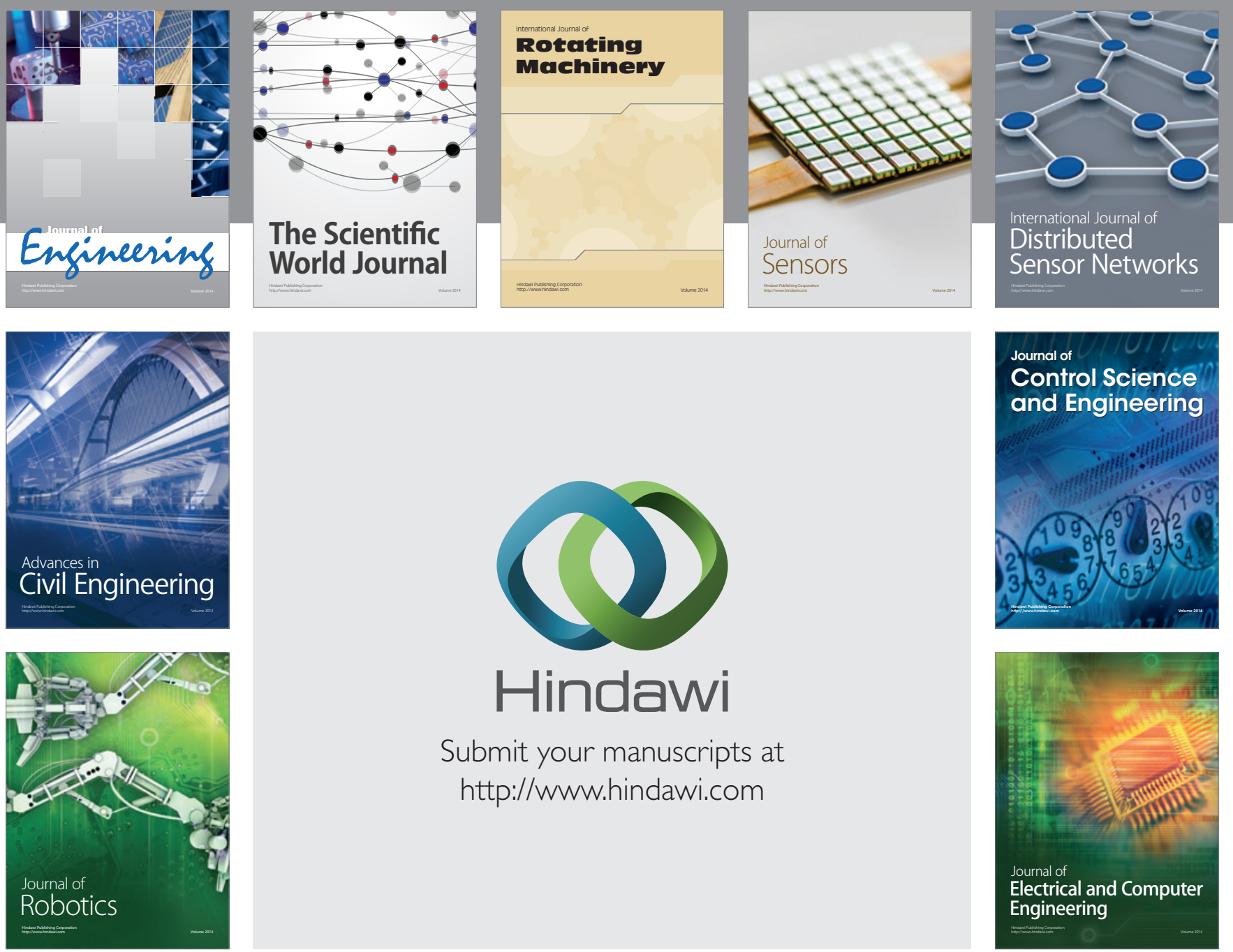

Submit your manuscripts at

http://www.hindawi.com
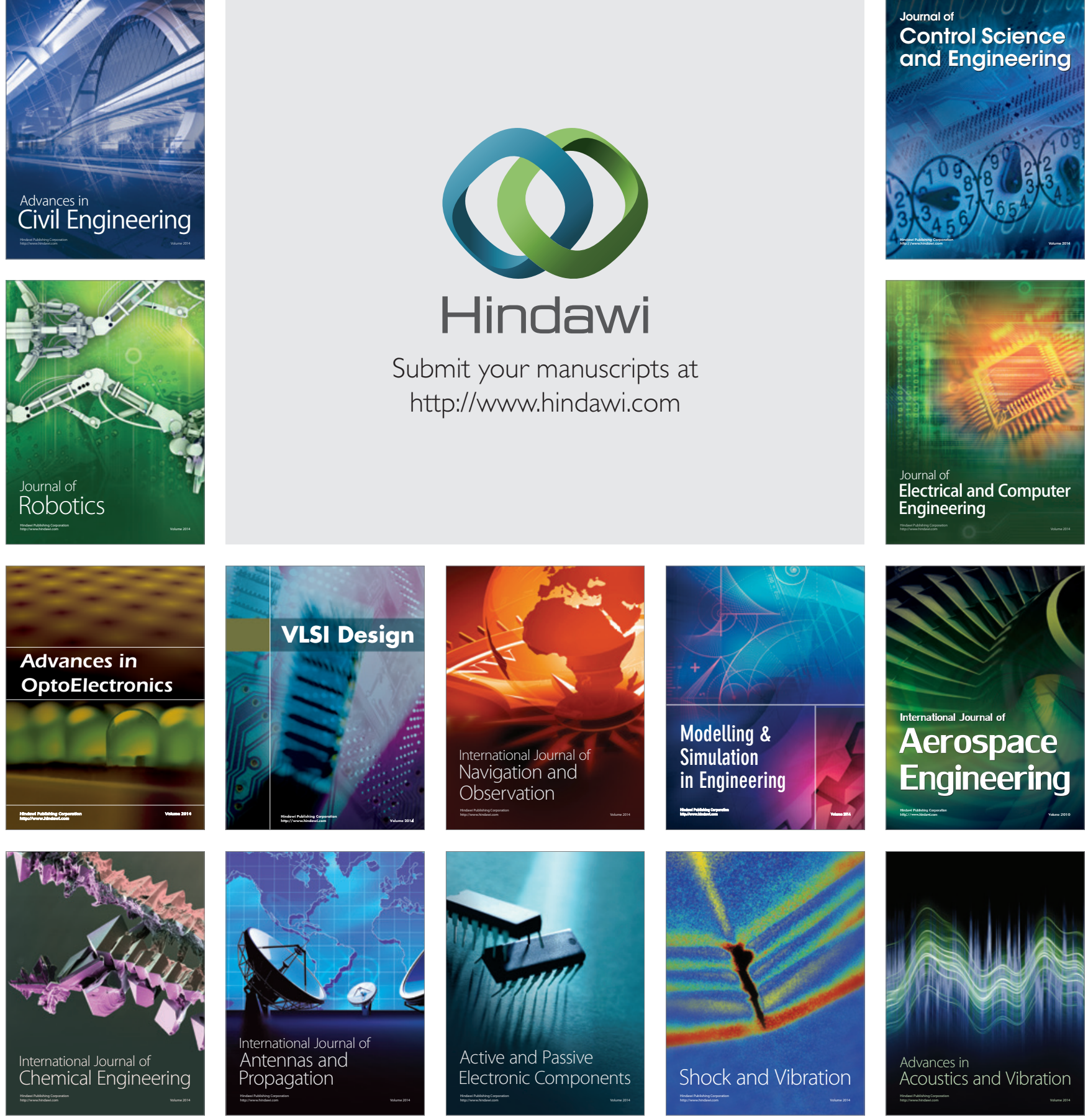